\title{
Is Gender a Driver of Topic Choice? A Comparative Keyword Analysis of Political Cable News Interviews
}

\author{
Mariasophia Falcone ${ }^{1} \&$ Belinda Crawford Camiciottoli ${ }^{2}$ \\ ${ }^{1}$ Independent scholar, Pisa, Italy \\ ${ }^{2}$ Dipartimento di Filologia, Linguistica e Letteratura, Università di Pisa, Pisa, Italy \\ Correspondence: Belinda Crawford Camiciottoli, Dipartimento di Filologia, Letteratura e Linguistica, Università \\ di Pisa, Pisa, Italy. E-mail: belinda.crawford@unipi.it
}

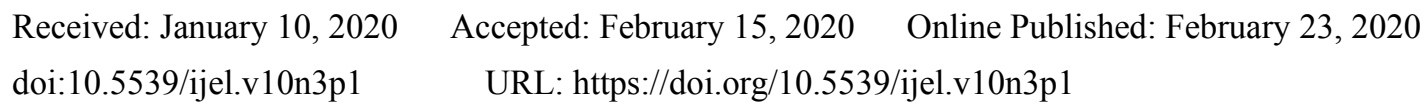

\begin{abstract}
Cable news networks have become an increasingly important source of political news in the United States. They wield considerable influence on public opinion, particularly in relation to current issues involving social roles and gender dynamics. This study offers insights into how the choice of topic in political cable news interviews may be influenced by the gender of participants. A corpus of 40 political cable news interviews was compiled and analyzed on the basis of various combinations of male and female interviewers and interviewees. Corpus software was implemented to extract keywords that were then grouped to identify prominent topics according to gender. Topics discussed exclusively among male participants were more issue oriented (i.e., immigration, healthcare, the economy, and gun control) as compared to those discussed exclusively among female participants that were more in social nature (i.e., personal matters, the Kavanaugh Supreme Court nomination, and tech giants in the context of social justice). Results showed that topics emerging from the female participants' discourse were aligned with some widely held perceptions of women's speech. At the same time, other features of the female participants' speech appeared to be driven largely by their professional and institutional roles, and thus, not aligned with stereotypical perceptions. The findings have implications for the role of media and cable news in contemporary American society in avoiding the perpetration of gender-related topic bias.
\end{abstract}

Keywords: corpus linguistics, cable news, news interviews, gender, keywords

\section{Introduction}

\subsection{The Role of Cable News Networks}

Since its early days, cable news in the United States has provided a distinctive way of presenting news content in the form of both news broadcasts and personality-based opinion shows during primetime. Among the various program offerings, news interviews of a political nature are particularly prominent. Recent research has revealed that cable news is the main source of political information for the majority of Americans (Mitchell, Gottfried, Barthel, \& Shearer, 2015). In addition, the most well-known cable news networks (e.g., MSNBC, Fox News, $\mathrm{CNN}$ ) have progressively resorted to providing more polarized content. As a result, the American audience has become less exposed to neutral news content and tends to follow news on networks that reflect their own political values (Martin \& Yurukoglu, 2017).

On a general level, the media continues to have a strong influence in people's everyday lives due to its well-established social role (Mullany, 1999). Furthermore, because of its institutionalized role, it contributes to and replicates the dominant power structure of society (Fairclough, 1995). Although social media are the preferred source of information among younger Americans, cable news as a traditional form of media is still considered the most helpful and reliable when it comes to political information (Mitchell et al., 2015). For this reason, investigating the discourse of cable news can provide important insights into how gender dynamics are portrayed in the media and how this influences their evolution in society. In particular, the central role of cable news in current American political discourse means that it inevitably has an impact on new issues that come into play on the political scene, including the rise of progressive political platforms especially related to gender, such as the Women's march and the \#MeToo movement. 


\subsection{Gender and Power Roles in News Interviews}

In all communicative contexts, language is affected by a set of variables that are either internal (i.e., our psychological state) or external (i.e., gender and power status) (Brownlow, Rosamond, \& Parker, 2003). According to previous research, aspects of women's speech can reflect their position in society. For example, some studies have characterized the role of women as subaltern, which is reflected and replicated in language (Lakoff, 1973; Coates, 2015). From this perspective, what has been described as typical elements of gendered speech ascribed to women, such as hedges, tag questions, and intensifiers, have all been associated with tentativeness and uncertainty (Brownlow et al., 2003). These elements are considered as the indicators of women's inferior social position (Fishman, 1990) and are purportedly aimed at seeking confirmation from the interlocutor (Lakoff, 1973).

As gender and, more specifically, gendered linguistic behavior is linked primarily to the power roles assigned to each gender in society, in news interviews these roles are also regulated by the fixed structure of the interview (Mullany, 1999; Macaulay, 2001). Indeed, the news interview is based on pre-allocated roles characterized by an irreversible power asymmetry (Montgomery, 2007; Blas Arroyo, 2010). Because of this pre-established and fixed nature of these roles (Montgomery, 2007), interviewers (hereafter IR) hold all the power, no matter their gender and in virtually any context. This fixed power asymmetry allows female speakers to emancipate themselves from the speech norms traditionally associated with their gender in other communicative contexts (Mullany, 1999). In fact, in these institutionalized communicative contexts, straying from the gendered norm results neither in the speech being perceived as marked nor as female speakers being perceived as deviant, as could otherwise occur based on the mismatched expectations of the interlocutor (Ochs, 1992). In the case of news interviews, the institutionalized nature of roles sets the expectations of the speakers and they appear mismatched only if the speakers deviate from their role of IR or interviewee (hereafter IE).

The predominance of the professional role is further corroborated by the research of Mulac, Seibold, and Farris (2000). Their study of communication in highly professional and institutionalized environments found that linguistic behavior was more reflective of the characteristics of the professional role, while bypassing gendered norms. Therefore, in institutionalized contexts speech norms are dictated primarily by role and power rather than by gender. Furthermore, according to Janssen and Murachver (2004), while speakers have a tendency to adjust their language to a given situation, in those cases in which they show gendered speech, they might do so because it is required by the topic discussed or the task performed. This result not only indicates that speakers can shift within a range of femininities and masculinities, but also that gender is done in relation to other people and based on different contexts (Coates, 2015; Mullany, 2010; Brownlow et al., 2003).

With particular reference to political news interviews, according to Mullany (1999), speakers can emancipate themselves from the speech norms of their gender without being perceived as deviant. More specifically, women who assume the role of the IR are able to take up an equal if not more powerful role compared to men. This would suggest that, when the role for women comes with authority and power, women's speech does not represent subalternity, lack of status, or tentativeness (Mullany, 1999; Lakoff, 1973). However, the data provided by Mullany (1999) could also have a second interpretation: women have no other option than to adapt to male speaking styles when they are in a position of power. Considering the lack representation of women in most institutions of our society, including politics and journalism, norms relating to interaction and speaking style have been modeled mostly on the basis of men's speech (Kendall \& Tannen, 1997).

The relation between power roles and gender in news interviews calls into question the concept of "rapport talk", defined by Tannen (1990, p. 77) as the talk of women that is usually aimed at establishing solidarity with the interlocutor as opposed to conveying information. Yet one of the purposes of the news interview as a genre is, in fact, to convey information, while also fulfilling entertainment purposes (O'Keeffe, 2006). Therefore, some of the elements that are associated with tentativeness and subalternity in everyday contexts have a different function in news interviews. For example, questions and tag questions representing typical features associated with female speech, in the case of news interviews, have the function of requesting information or, in an even more unbalanced situation, of confirming the information the IR already has. Thus, this shift in function makes such features typical of "rapport talk" more similar to "report talk" in news interviews (Tannen, 1990; Macaulay, 2001) (Note 1).

Because of its popularity in cable news, the political news interview has become one of the main media frameworks through which political discourse occurs. In fact, politicians are required to perform well during interviews, while journalists have to hold them accountable and manage the public debate on citizens' behalf (Clayman \& Heritage, 2004). Televised news interviews normally provide in-depth information on issues within 
the public debate, which is then viewed by a widespread audience not only in terms of geographical location, but also in terms of age, gender, and race. Because of the possibility of reaching such a vast audience, it is important to analyze the factors at play in conveying political information. As news interviews are highly interactive texts, gender and power roles are key factors influencing communication of which speakers may be unaware, and which can affect the way the audience sees and hears the issues discussed.

Although the relation between news interviews and gender has been studied extensively (e.g., Mullany, 1999; Macaulay, 2001; Brownlow et al., 2003), relatively little research has been conducted on the characteristics of gendered speech with particular regard to political cable news interviews. Therefore, the aim of this study is to investigate whether gender plays a role in political news interviews and to shed light on the impact it may have on topic choice.

To address the above issues, two research questions have been formulated as follows:

1) Are there gender-related differences in terms of choice of topic during political cable news interviews?

2) Do any patterns emerge in terms of female-exclusive or male-exclusive topics?

\section{Method}

\subsection{Source of Data and Corpus Overview}

The study is based on interviews selected from segments of different political programs on three cable news networks (i.e., CNN, Fox News, and MSNBC) dating from 2016 to 2018. Participants in the interviews are personalities who are well known both among television audiences and on the political scene, and are all native speakers of American English. The interviews were chosen based on four gender combinations of IR and IE (female IR and female IE, male IR and male IE, female IR and male IE, male IR and female IE), as well as variety in political ideology (Republican/conservative and Democrat/progressive). The two mixed gender IR/IE combinations were considered due to the different pre-allocated roles and to the potential effect of role distribution on gender dynamics.

The full transcripts of the interviews were retrieved from the cable channels' websites and, in some cases, they were extracted from the complete transcript of an entire program of which they represented a specific segment. During this process, there were some objective constraints in finding interviews that matched the criteria described above, in addition to the unavailability of some transcripts and differences in the number of interviews conducted across the networks during the timeframe of interest. For these reasons, the data collected for the study were limited to 40 interview transcripts in total with 10 for each gender combination. The transcripts were then compiled into a corpus of political cable news interviews (hereafter PCNI), which was further articulated into four subcorpora according to gender combination. The duration of the interviews ranged from a minimum of 7 minutes to a maximum of 15 minutes. The interviews included in the corpus were all one-on-one between the IR and the IE and were held in co-presence. Table 1 provides an overview of the PCNI.

Table 1. Structure of the PCNI

\begin{tabular}{ll}
\hline Subcorpora & Number of tokens \\
\hline Same-gender female & 21,300 \\
Same-gender male & 27,243 \\
Male IR and female IE & 22,081 \\
Female IR and male IE & $\underline{23,748}$ \\
Total & 94,372 \\
\hline
\end{tabular}

\subsection{Analytical Procedure}

In order to explore on possible gendered-related differences in the topic choices of IRs and IEs, a corpus-driven keyword analysis was conducted. In this process, keywords are detected by comparing the frequency of a word across two different corpora: the focus corpus under investigation and a reference corpus that is used for comparison. A reference corpus can be large and generally representative of given language or one that is selected as comparable in terms of particular features of interest (Scott, 2020). Those words that have a higher frequency in the focus corpus with respect to the reference corpus are considered keywords. Analyzing keywords can be useful to highlight frequent terminology or underlying topics in a particular corpus of interest.

For this study, the focus and reference corpora were based on groupings of the four subcorpora illustrated in Table 1 according to same-gender pairs vs. mixed-gender pairs. Then, keyword analyses were performed on the 
same-gender female subcorpus as the focus corpus with same-gender male corpus as the reference corpus (and vice-versa), as well as the male IR and female IE corpus as the focus corpus vs. the female IR and male IE corpus as the reference corpus (and vice versa). In this way, the keyword analysis could be finely tuned to pinpoint differences among the various subcorpora in the PCNI, beyond what could have been achieved by comparing them with a general English language reference corpus, such as the Corpus of Contemporary American English (Davies, 2008).

Sketch Engine, a corpus analysis software created by Adam Kilgarriff in 2003 and available online (Note 3), was the instrument used to perform the keyword analysis. A particular advantage of the keyword analysis tool provided in this software is that it allows researchers to adjust the criteria of the analysis to better fit the research. In this case, the focus criterion was set on very rare words, with the $N$ parameter (see the formula below) set at 0.001. This means that the tool will detect those words that are less common in the reference corpus with respect to the focus corpus. The minimum word frequency was set at five and all words had to contain alphanumeric characters, although non-alphanumeric characters were also allowed. This last option was selected in order to eventually include hyphenated words. The attribute selected for the search of keywords was lemmas (Note 2) in order to facilitate the grouping of words with a shared lemma. However, since the Sketch Engine lemma search is case sensitive, some of the results that shared a lemma were still presented as two separate entries and were later grouped together to simplify the analysis.

For each comparative analysis, the software generates a set of data: frequency counts, relative frequency, and keyness scores. Frequency counts indicate the number of occurrences of the word in the focus corpus and the reference corpus; relative frequency indicates the normalized frequency per million in relation to the number of tokens in the whole focus corpus. A keyness score is then calculated for words that are typical of the focus corpus with respect to the reference corpus. This calculation is performed using a simple math's method based on a variable that can be adjusted according to the focus criterion setting (Note 4). Therefore, a higher value is indicative of words that are relatively more frequent, while a lower value is indicative of words that are relatively less frequent. Keyness is calculated according to the following formula:

$$
\frac{f p m_{\text {rmfocus }}+N}{f p m_{\text {rmref }}+N}
$$

$\mathrm{fpm}_{\text {rmfocus }}$ indicates the normalized frequency of the word in the focus corpus, fpm $_{\text {rmref }}$ is the normalized frequency of the word in the reference corpus, and $N$ is defined as the smoothing parameter (Note 3).

For some of the keywords, a further analysis was performed with the tool Word Sketch that generates a word's collocates, as well as the words surrounding it in order to trace the word's grammatical relations.

Finally, an in-depth analysis was conducted on each keyword within its context of usage on the basis of concordance lines (i.e., vertical displays of occurrences of keywords with some co-text to the right and left). This analysis was performed in order to identify the topics to which keywords referred and to better understand how they were used by the speakers. After having established the topic category for each keyword, the keywords were grouped according to topic and then distributed according to gender.

\section{Results and Discussion}

\subsection{Comparative Keyword Analysis}

For each keyword analysis, the maximum number of items to be extracted was set at 100 . The most frequent keywords were related to the names of the interview participants or to various segments of the interviews (e.g., commercial break, end videoclip, inaudible), which corresponded to transcript metadata. These words were thus all excluded and the remaining top 15 keywords with a frequency count in the reference corpus of 0 were analyzed. Tables 2 and 3 show the results of the keyword analysis for the same-gender female and same-gender male corpora, respectively. The higher the keyness score, the stronger the "keyness" of that keyword. 
Table 2. Keyword analysis for same-gender female subcorpus

\begin{tabular}{llllll}
\hline Number & Keyword & $\begin{array}{l}\text { Frequency Count in } \\
\text { Focus Corpus }\end{array}$ & $\begin{array}{l}\text { Frequency Count in } \\
\text { Reference Corpus }\end{array}$ & Relative Frequency & Keyness Score \\
\hline 1 & Comey & 23 & 0 & 904.477 & $907,477.82$ \\
2 & Kavanaugh & 14 & 0 & 552.377 & $552,378.19$ \\
3 & McCabe & 9 & 0 & 335.100 & $355,100.63$ \\
4 & Presidency & 8 & 0 & 315.644 & $315,645.11$ \\
5 & Husband & 8 & 0 & 315.644 & $315,645.11$ \\
6 & Flip & 8 & 0 & 315.644 & $315,645.11$ \\
7 & Iraqi & 8 & 0 & 315.644 & $315,645.11$ \\
8 & Brett & 8 & 0 & 315.644 & $315,645.11$ \\
9 & Progressive & 7 & 0 & 276.189 & $276,189.60$ \\
10 & Liberal & 7 & 0 & 276.189 & $276,189.60$ \\
11 & Spouse & 6 & 0 & 236.733 & $236,734.08$ \\
12 & Protest & 6 & 0 & 236.733 & $236,734.08$ \\
13 & Leak & 6 & 0 & 236.733 & $236,734.08$ \\
14 & Hearing & 6 & 0 & 236.733 & $236,734.08$ \\
15 & Sorry & 5 & 0 & 197.278 & $197,278.57$ \\
\hline
\end{tabular}

Table 3. Keyword analysis for same-gender male subcorpus

\begin{tabular}{llllll}
\hline Number & Keyword & $\begin{array}{l}\text { Frequency Count in } \\
\text { Focus Corpus }\end{array}$ & $\begin{array}{l}\text { Frequency Count in } \\
\text { Reference Corpus }\end{array}$ & Relative Frequency & Keyness Score \\
\hline 1 & Gun & 25 & 0 & 755.059 & $755,059.89$ \\
2 & Kim & 14 & 0 & 422.833 & $422,833.98$ \\
3 & Refugee & 13 & 0 & 392.613 & $392,631.63$ \\
4 & Trade & 11 & 0 & 332.226 & $332,226.91$ \\
5 & Style & 10 & 0 & 302.024 & $302,024.56$ \\
6 & War & 9 & 0 & 271.821 & $271,822.20$ \\
7 & Semiautomatic & 9 & 0 & 271.821 & $271,822.20$ \\
8 & Nation & 9 & 0 & 271.821 & $271,822.20$ \\
9 & Conference & 9 & 0 & 271.821 & $271,822.20$ \\
10 & Warmbier & 9 & 0 & 271.821 & $271,822.20$ \\
11 & DACA & 9 & 0 & 271.821 & $271,822.20$ \\
12 & Assange & 9 & 0 & 271.821 & $241,619.85$ \\
13 & Summit & 8 & 0 & 241.619 & $241,619.85$ \\
14 & Rating & 8 & 0 & 241.619 & $241,619.85$ \\
\hline
\end{tabular}

The keyword analysis for the same-gender female subcorpus in Table 2 shows the presence of husband and spouse. This fact that these items emerged as key exclusively in the same-gender female subcorpus implies that private matters were discussed during interviews between female participants only, thus suggesting a lower level of distance between the participants and some degree of solidarity. In fact, women have a higher tendency to share personal stories and provide more personal information in order to establish solidarity (Hay, 2000; Tannen, 1990). Furthermore, language that recalls the social and emotional domain is also more common in women's speech (Mulac, 1998). This usage is illustrated in examples 1-3.

(1) That it's now fair game what people's - how people's spouses and significant others may differ with them. (CNN/IE-Kellyanne Conway)

(2) I don't remember the last time we saw somebody working for the president in a high-profile position when their spouse is saying critical things about them. (CNN/IR-Dana Bash)

(3) And it was a very difficult time. My husband and our dog, and parts of our house had to be quarantined. (Fox News/IE-Susan Collins)

Sorry was also present only in the same-gender female subcorpus. A further analysis was performed on this keyword with the tool Word Sketch, which identifies grammatical patterns of a given word or lemma. This analysis revealed that sorry occurred mostly preceded by the verb to be and most frequently in the combination I'm sorry. Interestingly, sorry was used only actively by the participants of this subcorpus and never in other ways, as in quoting someone else's words or events. However, the presence of sorry as a keyword does not 
necessarily imply that women quantitatively apologize more than men do. In fact, women and men associate apologies with different functions because they have a different idea of what requires an apology (Schumann \& Ross, 2010). For this reason, apologetic behavior takes different forms for women and men: apologizing for women is a way of showing courtesy and relation towards others (Tannen, 1996), as shown in examples 4 and 5. Therefore, the presence of sorry, in this case, could just imply a form of courtesy in a difficult communicative situation.

(4) Sorry, I don't see Michael doing that, despite the horrible witch-hunt and dishonest media. (CNN/IE-Kellyanne Conway)

(5) I'm sorry. It's hard for whom? (CNN/IE-Kellyanne Conway)

The same-gender subcorpora were also compared according to word class and noun abstractness in relation to the keywords that emerged. Results of this analysis are illustrated in Table 4.

Table 4. Word classes of keywords from the two same-gender subcorpora

\begin{tabular}{lll}
\hline Word Class & Same-gender female (\%) & Same-gender male (\%) \\
\hline Noun & 60.0 & 86.6 \\
Abstract noun & 33.3 & 61.5 \\
Verb & 13.3 & 6.7 \\
Adjective & 26.7 & 6.7 \\
Adverb & - & - \\
\hline
\end{tabular}

The same-gender male subcorpus presented more nouns ( $86.6 \%$ vs. $60.0 \%$ ) (e.g., Assange, Kim, DACA), the majority of which (61.5\%) were abstract nouns (e.g., nation, rating) compared to $33.3 \%$ abstract nouns in the same-gender female subcorpus. A higher presence of abstract nouns among male speakers can be linked to a higher variety in the topics discussed during the interviews. Nonetheless, a high presence of abstract nouns is a fundamental characteristic of political discourse (van Dijk, 1995). This could suggest that news interviews of this kind are more focused on information and political matters for men, while for women the focus is more on the personal aspects of the matters, as discussed previously.

The same-gender female subcorpus contained considerably more adjectives compared to the corresponding male subcorpus $(26.7 \%$ vs. $6.7 \%$, respectively) and therefore broadly in line with previous research (Lakoff, 1973; Crawford, 1995). However, the adjectives used by female speakers were context-specific and referred to the matters discussed in the interviews, as shown in examples 6-8. Therefore, in this case, their use of adjectives differs from previous characterizations of gendered female speech, which highlighted a higher presence of adjectives without a clear function (i.e., "empty adjectives" and more detailed speech overall; Crawford, 1995, p. 26). This difference is likely related to the political content of the interviews as well as the professional interactional context.

(6) I will say, if you look at what the Iraqi military has done in conjunction with us over the past several weeks and months now, really, they've stepped up to the plate. (Fox News/IE-Marie Harf)

(7) On lots of issues, I was really solid, that are progressive issues, women's reproductive freedoms [...]. (MSNBC/IE-Claire McCaskill)

(8) Senator Sanders undoubtedly has a huge role to play in the next iteration of liberal politics in this country. (MSNBC/IR-Rachel Maddow)

In the female same-gender group, gendered speech, though present, might not necessarily indicate subalternity or powerlessness. In fact, in most cases, female gendered language is used to focus on social topics, as well as the subjects' own relations and emotions, and does not appear to be aimed at being perceived as more likeable or more polite.

The results of the keyword analysis of the mixed-gender subcorpora are illustrated in Tables 4 and 5, respectively. 
Table 5. Keyword analysis for female IR and male IE corpus

\begin{tabular}{llllll}
\hline Number & Keyword & $\begin{array}{l}\text { Frequency Count in } \\
\text { Focus Corpus }\end{array}$ & $\begin{array}{l}\text { Frequency Count in } \\
\text { Reference Corpus }\end{array}$ & Relative Frequency & Keyness Score \\
\hline 1 & Rule & 19 & 0 & 666.433 & $666,433.83$ \\
2 & Repeal & 15 & 0 & 526.131 & $526,132.18$ \\
3 & Obamacare & 14 & 0 & 491.056 & $491,056.77$ \\
4 & Goal & 13 & 0 & 455.980 & $455,981.36$ \\
5 & Obstruction & 12 & 0 & 420.905 & $420,905.95$ \\
6 & Staffer & 11 & 0 & 385.830 & $385,830.53$ \\
7 & Fire & 11 & 0 & 385.830 & $385,830.53$ \\
8 & Insurance & 10 & 0 & 350.745 & $350,755.12$ \\
9 & Replace & 9 & 0 & 315.679 & $315,679.71$ \\
10 & Conservative & 9 & 0 & 315.679 & $315,679.71$ \\
11 & Compromise & 9 & 0 & 315.679 & $315,679.71$ \\
12 & Balance & 9 & 0 & 315.679 & $315,679.71$ \\
13 & Preview & 8 & 0 & 280.603 & $280,604.30$ \\
14 & Nice & 8 & 0 & 280.603 & $280,604.30$ \\
15 & Dreamer & 8 & 0 & 280.603 & $280,604.30$ \\
\hline
\end{tabular}

Table 6. Keyword analysis for male IR and female IE corpus

\begin{tabular}{llllll}
\hline Number & Keyword & $\begin{array}{l}\text { Frequency Count in } \\
\text { Focus Corpus }\end{array}$ & $\begin{array}{l}\text { Frequency Count in } \\
\text { Reference Corpus }\end{array}$ & Relative Frequency & Keyness Score \\
\hline 1 & Kavanaugh & 18 & 0 & 671.817 & $671,818.27$ \\
2 & Testimony & 13 & 0 & 485.201 & $485,202.36$ \\
3 & Amazon & 12 & 0 & 447.878 & $447,879.18$ \\
4 & Boy & 11 & 0 & 410.555 & $410,556.00$ \\
5 & Brett & 10 & 0 & 373.232 & $373,323.81$ \\
6 & Sentence & 10 & 0 & 373.232 & $373,323.81$ \\
7 & Platform & 10 & 0 & 373.232 & $373,323.81$ \\
8 & Pardon & 9 & 0 & 335.909 & $335,909.63$ \\
9 & Child & 9 & 0 & 335.909 & $335,909.63$ \\
10 & Treasury & 9 & 0 & 335.909 & $335,909.63$ \\
11 & Trip & 8 & 0 & 298.585 & $298,586.45$ \\
12 & Tech & 8 & 0 & 298.585 & $298,586.45$ \\
13 & Compelling & 8 & 0 & 298.585 & $298,586.45$ \\
14 & Ford & 8 & 0 & 298.585 & $298,586.45$ \\
15 & Sexual & 6 & 0 & 223.939 & $223,940.09$ \\
\hline
\end{tabular}

The analysis for the two mixed-gender subcorpora was based on the assumption that the IR is the participant introducing the topics. This is required by the IR role as the participant with the most power and whose function is usually that of setting the agenda and topics (Montgomery, 2007). Furthermore, it is highly unlikely that the IE, as the one being questioned, would introduce a topic, as this could possibly impede smooth communication. For this reason, the analysis of the mixed-gender corpora takes in consideration gender as a factor according to which IEs, being in a less powerful position, are being questioned.

Because gender influences speech also based on gender combinations, mixed-gender groups present differences compared to same-gender groups (Aries, 1998). However, in mixed-gender contexts both genders have shown the tendency to accommodate the interlocutor in order to have smooth communication and positive evaluation (Mulac, Wiemann, Widenmann, \& Gibson, 1988). In fact, overall, the mixed-gender subcorpora presented more quantitative similarities compared to the two previous subcorpora. In particular, both corpora have a higher number of nouns ( $73 \%$ for the female IR and male IE subcorpus and $80 \%$ for the male IE and female IR subcorpus), and an equal number of adjectives in their keywords (13.3\%), as illustrated in Table 7. 
Table 7. Word classes for mixed-gender subcorpora

\begin{tabular}{lll}
\hline Word Class & Female IR - Male IE (\%) & Male IE - Female IE (\%) \\
\hline Noun & 73.4 & 80 \\
Abstract noun & 63.6 & 41.6 \\
Verb & 13.3 & 6.7 \\
Adjective & 13.3 & 13.3 \\
Adverb & - & - \\
\hline
\end{tabular}

Although quantitative similarities were present in relation to nouns, the female IR and male IE subcorpus presented a higher number of abstract nouns (63.6\% vs. $41.6 \%)$. This aspect is more similar to same-gender male subcorpus more than the other subcorpora. The high number of nouns can be linked to a variety of topics. In fact, keywords such as rule, insurance, Obamacare, Amazon, pardon and treasury all refer to issues of the current public debate (see examples 9-10). No keywords that referred to personal matters were found, implying a higher focus on information during these interviews as opposed to personal matters.

(9) There are not many people that can speak with real credibility to conservatives but can also speak to moderates. (CNN/IE-Ted Cruz)

(10) The biggest reason people hate Obamacare is their premiums have skyrocketed. (CNN/IE-Ted Cruz)

(11) Let's go to the way the Treasury Department is run, because you look at it right now and I'll draw your attention to a very simple illustration. (MSNBC/IR- Ari Melber)

The same percentage of adjectives for both subcorpora (13.3\%) seems to confirm once again that, in the case of political news interviews, women's gendered speech differs from that of everyday contexts. In fact, in this case, a higher presence of adjectives used by women, which is typical of an overall more detailed speech (Crawford, 1995), was not found. Both genders seemed to use adjectives in the same way and in relation to the matter discussed, as shown in examples 12 and 13.

(12) There was no corroboration that nobody could deny that her testimony wasn't compelling. (Fox News/IE-Sarah Sanders)

(13) Well, I think he's certainly no more conservative than Scalia. (MSNBC/IE- Lindsey Graham)

Keyword overlapping was noticed between the same-gender female subcorpus and the male IR and female IE subcorpus. In particular, Kavanaugh and Brett were present in both subcorpora. This would indicate that it is the IE's gender that drives the topic choices in mixed-gender news interviews. Nonetheless, the male IR and female IE keywords revealed recurring topics compared to the same-gender female corpus, as will be discussed in the next subsection.

\subsection{Topic Distribution}

The 60 keywords that emerged from the analysis of the PCNI illustrated in the previous section were then grouped according to 10 topic categories. The criterion for identifying these categories was the presence of at least two keywords that referred to the same matter. In order to clearly distinguish the topics to which the keywords referred, a further analysis of concordance lines was performed. Only in two cases (i.e., goal and child) it was not possible to identify a single topic to which the keyword referred, either because their meanings were too vague or because they were present in relation to different topics. Therefore, these two items were eliminated, leaving a total of 58 keywords that were distributed across 10 categories.

Then, for each topic category, their distribution according to gender was analyzed. The topic distribution according to gender is illustrated in Table 8. Once again, for the mixed-gender corpora, topics were assigned to either gender according to the gender of the IEs. As the IRs always introduce the topic in line with their role to asks questions from a more powerful position (Montgomery, 2007), it was assumed that the gender of the IE would play a primary role in the choice of topic. 
Table 8. Topic distribution based on gender

\begin{tabular}{llll}
\hline Topic & Overall keyword distribution (\%) & Use by males (\%) & Use by females (\%) \\
\hline Trump presidency & 31.03 & 55 & 45 \\
Immigration & 6.90 & 100 & - \\
Economy & 1.73 & 100 & - \\
Gun control & 3.44 & 100 & - \\
Healthcare & 6.90 & 100 & - \\
Personal matters & 5.17 & - & 100 \\
Foreign policy & 13.80 & 75 & 25 \\
Kavanaugh nomination & 17.24 & - & 100 \\
Tech Giants & 5.17 & - & 100 \\
Politics & 8.62 & 40 & 60 \\
\hline
\end{tabular}

As can be seen from the table, the most common topic overall was the Trump presidency, accounting for $31.03 \%$ of the topics identified. Although the gender distribution appears to be fairly balanced, some qualitative difference could be detected. In fact, it would appear that women focused more on the people involved in the matters of the Trump Presidency (e.g., Comey, McCabe) as shown in examples 14 and 15, while men focused more on the implication of such matters (rule, obstruction), as shown in examples 16 and 17.

(14) That is what I'm basing that on and I want to know what Comey says about this. (MSNBC/IE-Amy Klobuchar)

(15) Andrew McCabe, it's admitted now that he lied four times, at least three under oath. (CNN/IE-Kellyanne Conway)

(16) There is a credible case of obstruction of justice against the president of the United States. (MSNBC/IE-Richard Blumenthal)

(17) Our goal is to vindicate the rule of law. (CNN/IE- Jerry Nadler)

This pattern would appear to reflect the idea according to which men focus more on information and women on the social side of such information (Hay, 2000; Tannen, 1990). However, it has to be taken into account that women might be asked about issues from a personal or social viewpoint as opposed to the matter itself. In this case, the media would be perpetrating a stereotype according to which women are more prone to gossip or discuss people rather than facts (Tannen, 1990).

The second most common topic was the Kavanaugh nomination (17.24\%). However, it was discussed only by women, which might suggest gender-driven behavior in considering the issue as somewhat female exclusive. In 2018, Brett Kavanaugh was nominated by President Trump for Associate Justice of the Supreme Court of the United States. During his confirmation process, Dr. Christine Blasey Ford and other women from Kavanaugh's past came forward with accusations of sexual assault and misconduct, which eventually led to an FBI investigation. Both Kavanaugh and Ford testified before the Senate Judiciary Committee, although Kavanaugh's nomination to the Supreme Court was later confirmed (Rocha, Tatum, \& Ries, 2018). The Kavanaugh confirmation process and hearing was one of the most discussed issues of 2018, which was scrutinized by all media outlets extensively. However, according to these findings only women discussed it.

Because of the nature of this issue involving matters such as sexual assault and toxic masculinity, which go beyond the nomination to the Supreme Court, the fact that in the interviews of the PCNI it was only discussed by women highlights an interesting gender-related pattern. These findings suggest that such issues are considered to be relevant to women and not to men. In contrast, men who gave interviews during the same period of time were not asked about this issue, perhaps because it might have been considered not a 'male issue', following Ziegler and White (1990). While there is rising media awareness in relation to topics of this nature, the way the media is addressing them might be perpetrating a gender-exclusive behavior by only considering them from an exclusively female perspective.

The topic of foreign policy (accounting for 13.8\%) also presented some notable quantitative and qualitative differences between the two genders. While for male participants the issue of foreign politics was discussed more overall and from a perspective of international relations (e.g., the keywords Summit, Kim, Assange), for women the only keyword linked to this topic was Iraqi. A further analysis of this keyword with the Word Sketch tool revealed that, as a modifier, it occurred more frequently with army, military, military force, security forces, and troops, which all refer to the defense semantic domain. While the issue of defense might be considered male dominated, it could be argued that discussing foreign policy from a security perspective might actually reflect the 
female stereotype according to which women must appear maternal and protective. This could be interpreted as a common double bind that many women in politics face. Specifically, women should adhere to the stereotype of appearing maternal or feminine (with the way they talk and what they say), although that is not accepted in politics. However, if they adhere more to male speaking styles, they are regarded suspiciously, while if they appear too womanly, they risk of being labeled as incompetent (Tannen, 1990).

Politics in general (8.62\%) was also a relatively common topic category. According to van Dijk (1995), one of the most typical characteristics of political discourse is that it is self-reflexive, meaning that it can have itself as a topic while also covering a series of various other topics. For example, here keywords such as liberal, conservative, compromise, platform and progressive have been grouped under the topic category of politics. Table 8 also shows that three topics were discussed by men only: healthcare, gun control and immigration. All three topics have been at the center of the public debate in the United States for some time now and, while it would appear predictable that they were discussed during the interviews, it is fairly unusual that they were not present in the interviews with women.

The issue of tech giants $(5.7 \%)$ and the fact that they have few to no regulations have been discussed recently in the public debate in the United States. In fact, it has been addressed not from a technical point of view, but rather from a regulation point of view. Very often this issue has been associated with consumer protection, privacy rights and social justice. In this case, the presentation of this issue from a protection viewpoint takes a similar perspective as that of the issue of defense described above, in which women adhere to the idea of being protective of citizens, in this case, against big corporations, as illustrated in examples 18 and 19.

(18) What I'm talking about is how big these tech giants have gotten. (CNN/IE-Kamala Harris)

(19) Entrepreneurs who want to put their products on Amazon, or on Google and who are at an enormous competitive disadvantage because of Amazon or Google. (MSNBC/IE-Elizabeth Warren)

In contrast, of the three other topics discussed only by women, one does not refer to matters of the public debate, namely personal matters. As previously mentioned, keywords that referred to aspects of personal life were found only in the subcorpora in which women were present and this could suggest an influence of gender on topic choice. Although recent changes in the news interview genre have shown a tendency to shift more towards personal information with less fact-based information (Montgomery, 2008), in this case, signals of this tendency are only present in news interviews with women participants. This is also true for same-gender female interviews, suggesting that in same-gender groups, women are more prone to share personal information, even if they also could be questioned more by men on these matters. Furthermore, as men discussed more topics linked to current affairs (defined as 'masculine' news) (Ziegler \& White, 1990), while women discussed more topics of a social nature, the reflection of this pattern in cable news reveals that gender does appear to play a role in the choice of topics discussed in news interviews.

\section{Conclusions}

In this study, a corpus of political cable news interviews articulated into four subcorpora of gender-based IR/IE combinations was analyzed to shed light on how gender may influence the choice of topic. To accomplish this objective, it was first necessary to determine which topics were discussed the most frequently by all the interview participants, and then look for possible gender-related differences. The corpus software Sketch Engine was implemented to identify the main topics of the interviews by means of keyword analysis, which extracted the most frequent words across the four subcorpora. The retrieved keywords were then compared to detect any gender-related trends and patterning.

With reference to the first research question posed at the outset, the keyword analyses of the four subcorpora revealed some differences in terms of topic choice. Although the Trump presidency was not surprisingly the most frequent topic, some differences in how it was discussed did emerge: women spoke more about the people involved in the Trump Presidency, while men spoke more about issues related to the Trump presidency. A particularly interesting result refers to the Kavanaugh nomination as the second most frequent topic that was discussed among women only. Other topics discussed exclusively by women were personal matters and tech giants, while topics that were discussed only by men were, again, more issues-oriented: immigration, the economy, healthcare and gun control. The topic of foreign policy was also approached differently by men and women. Specifically, the only related keyword used by women was Iraqi and thus restricted to a military context, whereas men discussed foreign policy in relation to a broader array of topics.

In terms of emerging patterns linked to men's vs. women's choice of topics (the second research question), the alignments that were found reflected to some extent pre-existing notions of gendered speech (e.g., Tannen, 1990; 
Mulac, 1998; Hay, 2000). For example, the topics related to personal matters were exclusive to the discourse of the women participants. Interestingly, however, this result also points to lower social distance between the interlocutors, which is not typical of news interviews. Topics with social and emotional implications were also exclusive to women. For example, the focus on the Kavanaugh nomination involving allegations of sexual misconduct and the tech giants in the context of social justice is in line with perceptions that women's speech is more emotionally oriented. Moreover, this trend was corroborated by the follow-up analysis of the keywords with Word Sketch that revealed a higher presence of names referring to people involved in the matters discussed for women versus more frequent abstract nouns for men. Indeed, the women participants were asked to weigh in on issues from a personal standpoint, while men were asked to respond from an ideological one.

Nevertheless, not all the features of the female participants' speech conformed to widely held perceptions. In fact, differently from everyday conversation, the news interview is influenced by its irreversible power structure, so that some elements typically associated with female discourse do not necessarily imply powerlessness. For instance, the higher presence of adjectives here was linked to the matter being discussed in the interviews and could not be defined as the use of empty adjectives (Crawford, 1995). In the same way, the presence of sorry in the same-gender female corpus indicated a willingness to show courtesy but not from a subaltern position, considering that it involved someone of the same gender. Thus, this analysis revealed that characteristics of female-gendered speech, though present in the PNIC, do not reflect subalternity or tentativeness. However, even in highly institutional context with strict formal constraints, gender appears to still be a key factor that influences communication in underlying complex ways. In this case, gender emerged through the choice of topics and in how they were presented and discussed.

In order to corroborate the above results and to acquire additional insights into gender-related differences in the discourse of cable news political interviews, it would be necessary to conduct further research. For example, this analysis was based on interviews that took place in a timeframe closely linked to critical elections involving very controversial political figures (i.e., 2016-2018), which could have had a considerable impact on the findings. It would thus be important to analyze political cable news interviews from non-election periods, as well as from earlier timeframes that would further enhance our understanding of diachronic variation in gendered speech patterns. Moreover, other features of interviews beyond topic choice (e.g., interactional and interpersonal linguistic elements) would also be interesting candidates to explore for more insights into gender-related trends in political interviews.

To conclude, this study has contributed to our knowledge of the role in gender in the choice of topic in political cable news interviews as an institutionalized communicative context. How topics are presented in these interviews is also particularly relevant in terms of audience perception. In fact, considering the prominent role of media and cable news in American society today, if they are perpetrating latent bias or stereotypes, they could be influencing the audience in inappropriate ways. In particular, if certain topics are perceived as female or male exclusive, this will inevitably affect the way such topics are discussed in the public debate. Yet, overall, the gender-related differences in how certain topics are discussed in political cable news interviews identified in this study can be interpreted in a positive sense. Even if there remain some concerning aspects of how some topics are represented by the media, the fact that they have been discussed extensively reveals their strong influence on the current public debate and the media's willingness to address them.

\section{Acknowledgments}

The authorship of the article is allocated as follows: Mariasophia Falcone was responsible for the sections 1, 2 and 3, while Belinda Crawford Camiciottoli was responsible for section 4, the abstract, and the overall coherence of the paper.

\section{References}

Aries, E. (1998). Gender differences in interaction: A reexamination. In D. J. Canary \& K. Dindia (Eds.), Sex Differences and Similarities in Communication (pp. 65-81). Mahwah, NJ: Erlbaum.

Blas Arroyo, J. L. (2010). Interpersonal issues in political discourse. In M. A. Locher \& S. L. Graham (Eds.), Interpersonal Pragmatics (pp. 405-435). Berlin, Germany: Mouton.

Brownlow, S., Rosamond, J. A., \& Parker, A. J. (2003). Gender-linked linguistic behavior in television interviews. Sex Roles, 49, 121-133. https://doi.org/10.1023/A:1024404812972

Clayman, S., \& Heritage, J. (2004). The news interview: Journalists and public figures on the air. Cambridge, England: Cambridge University Press.

Coates, J. (2015). Women, men and language: A sociolinguistic account of gender differences in language. 
London, England: Routledge. https://doi.org/10.4324/9781315645612

Crawford, M. (1995). Talking difference: On gender and language. London: Sage.

Davies, M. (2008). The corpus of contemporary American English (COCA): 600 million words, 1990-present. Retrieved from https://www.english-corpora.org/coca

Fairclough, N. L. (1995). Critical discourse analysis: Papers in the critical study of language. London, England: Longman.

Fishman, P. (1990). Conversational insecurity. In D. Cameron (Ed.), The feminist critique of language (pp. 234241). London, England: Routledge

Hay, J. (2000). Functions of humor in the conversations of men and women. Journal of Pragmatics, 32, 709-742. https://doi.org/10.1016/S0378-2166(99)00069-7

Janssen, A., \& Murachver, T. (2004). The relationship between gender and topic in gender-preferential language use. Written Communication, 21(4), 344-367. https://doi.org/10.1177/0741088304270028

Kendall, S., \& Tannen, D. (1997). Gender and language in the workplace. In R. Wodak (Ed.), Gender and discourse (pp. 81-105). London, England: Sage. https://doi.org/10.4135/9781446250204.n5

Kilgarriff, A. (2009). Simple maths for keywords. In M. Mahlberg, V. González-Diaz \& C. Smith (Eds.), Proceedings of the Corpus Linguistics Conference (CL2009). Retrieved from https://www.sketchengine.eu/wp-content/uploads/2015/04/2009-Simple-maths-for-keywords.pdf

Kilgarriff, A., Baisa, V., Bušta, J., Jakubíček, M., Kovář, V., Michelfeit, J., ... Suchomel, P. (2014). The Sketch Engine: Ten years on. Lexicography, 1, 7-36. https://doi.org/10.1007/s40607-014-0009-9

Lakoff, R. (1973). Language and woman's place. Language in Society, 2, 45-80. https://doi.org/10.1017/S0047404500000051

Macaulay, M. (2001). Tough talk: Indirectness and gender in requests for information. Journal of Pragmatics, 33, 293-316. https://doi.org/10.1016/S0378-2166(99)00129-0

Martin, G. J. \& Yurukoglu, A. (2017). Bias in cable news: Persuasion and polarization. American Economic Review, 107, 2565-2599. https://doi.org/10.1257/aer.20160812

Mitchell, A., Gottfried, J., Barthel, M., \& Shearer, E. (2015, July 14). The evolving role of news on Twitter and Facebook. Pew Research Center. Retrieved from https://www.pewresearch.org

Montgomery, M. (2007). The discourse of broadcast news. London, England: Routledge.

Montgomery, M. (2008). The discourse of the broadcast news interview. Journalism Studies, 9, 260-277. https://doi.org/10.1080/14616700701848303.

Mulac, A. (1998). The gender-linked language effect: Do language differences really make a difference? In D. J. Canary \& K. Dindia (Eds.), Sex differences and similarities in communication (pp. 127-153). Mahwah, NJ: Erlbaum.

Mulac, A., Seibold, D. R., \& Farris, J. L. (2000). Female and male managers' and professionals' criticism giving: Differences in language use and effects. Journal of Language and Social Psychology, 9, 389-341. https://doi.org/10.1177/0261927X00019004001

Mulac, A. M., Wiemann, J. M., Widenmann, S. J., \& Gibson, T. W. (1988). Male/female language differences and effects in same-sex and mixed-sex dyads: The gender-linked language effect. Communication Monographs, 55, 315-335. https://doi.org/10.1080/03637758809376175

Mullany, L. (1999). Linguistic politeness and sex differences in BBC Radio 4 broadcast interviews. Leeds Working Papers in Linguistics and Phonetics, 7, 119-142.

Mullany, L. (2010). Gender and interpersonal pragmatics. In M. A. Locher \& S. L. Graham (Eds.), Interpersonal Pragmatics (pp. 225-253). Berlin, Germany: Mouton.

O'Keeffe, A. (2006). Investigating media discourse. London, England: Routledge. https://doi.org/10.4324/9780203015704

Ochs, E. (1992). Indexing gender. In D. Alessandro \& C. Goodwin (Eds.), Rethinking Context: Language as an Interactive Phenomenon (pp. 335-359). Cambridge, England: Cambridge University Press.

Rocha, V., Tatum, S., \& Ries, B. (2018, September). The Kavanaugh hearing. CNN. Retrieved from https://edition.cnn.com/politics/live-news/kavanaugh-hearing-dle/index.html 
Schumann, K., \& Ross, M. (2010). Why women apologize more than men: Gender differences in thresholds for perceiving offensive Behavior. Psychological Science, 21(11), 1649-1655. https://doi.org/10.1177/0956797610384150

Scott, M. (2020). WordSmith tools help. Stroud: Lexical Analysis Software. Retrieved from https://lexically.net/downloads/version7/HTML/referencecorpus.html

Tannen, D. (1990). You just don't understand: Women and men in conversation. New York, NY: William Morrow.

Tannen, D. (1996). I'm sorry, I won't apologize. Retrieved December 28, 2019 from https://static1.squarespace.com/static/5523ffe4e4b012b2c4ebd8fc/t/5617e0f5e4b0b73949ee422f/14444054 93823/i\%27m+sorry+i+won\%27t+apologiza.pdf

van Dijk, T. A. (1995). What is political discourse analysis? In J. Blommaert \& C. Bulcaen (Eds.), Political linguistics (pp. 11-52). Amsterdam, Netherlands: Benjamins. https://doi.org/10.1075/bjl.11.03dij

Ziegler, D., \& White, A. (1990). Women and minorities on network television news: An examination of correspondents and newsmakers. Journal of Broadcasting and Electronic Media, 34, 215-223. https://doi.org/10.1080/08838159009386737

\section{Notes}

Note 1. Tannen (1990) distinguished between two different speech styles for men and women as "report-talk" and "rapport talk", respectively. The difference is defined by two different aims: while women use language to establish intimacy and relations, men use it to focus on information and as a way to hold status.

Note 2. A lemma is a word root (e.g., leak) from which other related words are formed (e.g., leaks, leaked, leaker, leaking), and correspond to the form that can be found in dictionaries.

Note 3. https://app.sketchengine.eu/

Note 4. For a detailed explanation of the parameters for keyword analysis applied in Sketch Engine, see Kilgarriff (2009) and Kilgarriff et al. (2014).

\section{Copyrights}

Copyright for this article is retained by the authors, with first publication rights granted to the journal.

This is an open-access article distributed under the terms and conditions of the Creative Commons Attribution license (http://creativecommons.org/licenses/by/4.0/). 